\title{
Teaching (with) Postcards: Approaches in the classroom, the field, and the community
}

\author{
Mascha Gugganig and Sophie Schor \\ Technical University Munich, Independent Scholar
}

\begin{abstract}
This article showcases the pedagogical possibilities of working with postcards for teaching anthropology and related disciplinary fields by introducing a set of multifaceted tools and examples. It provides a framework for tangible reflexive teaching practices and a research methodology that supports, both intellectually and emotionally, a vibrant and mobile community of scholars. We commence with discussing the (widely undervalued) role of postcards as a research subject in the social sciences, and subsequently provide an overview of the emergence of the postcard. Examples from the arts, literature, teaching and research then offer inspiration for engaged and creative teaching formats. These cases support our claim that as a seemingly 'anachronistic' object of communication, postcards are useful for teaching in the classroom, for teaching ethnography, and for community-based work. In fact, as a traveling communication device, the repurposed postcard lends itself to connect the oft-physically and conceptually divided spaces of the classroom and the ethnographic 'field.' Concurrently, the opening of postcards, both in a conceptual and material sense, allows for a critique of the medium's historical use in exoticizing the 'other.' We thus extend the pedagogical potentials to use postcards for innovative approaches in ethnographic research, public anthropology, and applied community work.
\end{abstract}

\section{Researching Postcards}

Historically, there has been a prejudice in academic research against postcards as banal expression of popular culture (Ferguson, 2005). Yet how postcards have been understood is not unrelated to their academic contexts. Social sciences, like anthropology, were coming of age at the same time as positivism, photography (Berger \& Mohr, 1982) - and postcards. More critical research on postcards only commenced in the postmodern era when the role of (visual) representation was under scrutiny (Ferguson, 2005; Moors \& Machlin, 1987; Peterson, 1985).

Besides this low culture perception of postcards, they have also often been dismissed as an unclear genre, where content - i.e. the written message - may not 'match' the form - i.e. the visual representation of a place, people or subject (Andriotis \& Mavrič, 2013, p. 31; Östman, 2004, p. 8; Schor, 2017). Consequently, researchers tended to focus on one modality only, primarily the image (Baldwin, 1988; Hall \& Gillen, 2007). Yet postcards have been popular exactly because of their multiple functions as collectible, ritual communication and (visual) gift exchange (Rogan, 2005, p. 18). Contemporary definitions of postcards as an "incredible chameleon" with a "chimeric nature" (Ferguson, 2005, p. 168) and its "enmeshed functions" (Rogan 2005, p. 1) indicate a shift towards an analysis and appreciation of postcards as "multifaceted objects" (Andriotis \& Mavrič, 2013, p. 35).

Social scientists have thus far not fully explored the potential of working with postcards. Exceptions include researchers that use the medium and idiom of postcards as a tool to evaluate research methodologies (Allen \& Rumbold, 2004), while a feminist research collective uses postcards to prepare and reflect on an academic conference panel (Adjin-Tettey et al., 2008). Before turning to examples from the arts, literature, and academic work, an overview of the beginnings of the postcard is insightful. 


\section{The Emergence of the Postcard}

Different accounts exist as to the origin of the postcard, with the most common reference citing October 1 st, 1869—a good 150 years ago—as the first officially issued postcard in Austria (Brady, 1969, p. 848; Iken, 2019). Other accounts suggest that the practice of "exchanging messages on illustrated cards" can be traced even further back to tenth-century East-Asia (Goldsworthy, 2010, p. 152). Over the early decades, postcards went through several format changes; from prepaid cards to nonpictorial stationary cards (with one side for the message, the other for the address), to the French carte de voeux (greeting cards), to the picture postcard we now associate with a postcard (Ferguson, 2005; Moran, 2005; Ripert \& Frère, 1983, p. 19). Mass printing technologies in the late 1890s led to the replacement of the message side with a photograph, where now a postcard's front side (recto) was for the address and stamp only, and the back side (verso) showed an image (Brady, 1969; Ferguson, 2005, p. 170). As a result, people often wrote short messages onto a picture's blank spots (Rogan, 2005, p. 10; Kelly, 2004, p. 102). This form of postcard writing led to a change from elegantly written expressions to short staccato phrases in the effort to economize on space (Brady, 1969, p. 850) - not unlike how in contemporary times Twitter has transformed writing habits into pithy capsules. In 1902, the British postal authority further standardized postcards by dividing the front side to make space for writing a personal message next to the address, thus establishing the classic format of what is nowadays associated with a postcard (see Kelly, 2004, p. 102).

The Golden Age of postcards peaked in 1914 with 200 to 300 billion produced and sold postcards (Ferguson, 2005, p. 170; Rogan, 2005, p. 18). Compared to the letter, the postcard was a more democratic avenue that allowed anyone with any level of literacy to communicate, particularly in rural areas (Gillen, 2013; Staff, 1966). In places with well-established postal infrastructures (i.e. in Europe and North America) postcards constituted a quick mode of exchange between two parties, often also with both being on the move (Andriotis \& Mavrič, 2013; Rogan, 2005). In some places, like Berlin, mail was delivered up to eleven times a day, which in its frequency, and considering the temporality at the time, comes very close to the contemporary speed of sending an email or text message (Iken, 2019).

The Golden Age also perpetuated exoticizing imaginaries of far-away places and people, which went hand in hand with an emergent global tourism industry (Urry, 1990; Goldsworthy, 2010). This mutual growth can be read in the context of free market and imperial forces, which often perpetuated racist depictions of places and peoples (Albers \& James, 1988; Ferguson, 2005, p. 174; Peterson, 1985). Tourism researcher Peter Burns notes that postcards reinforced the exoticized representations of the Eastern 'other' (2004, p. 271), while geographers Waitt \& Head (2002) attest that postcards perpetuated the frontier myth of the Australian outback. By labelling who and what places are the 'foreigner' or 'enemy,' postcards powerfully shaped discourses and imaginaries of the 'other.'

This is also seen in The Colonial Harem which critically compiles an 'album' of postcards—all of Algerian women in varying stages of undress - and highlights the colonial and gendered gaze of French postcards (Alloula, 1986). While the commerce of postcards enabled structures of domination and state violence, Goldsworthy's postcolonial critique of Moroccan postcards further demonstrates how postcards offered space for resistance and the restructuring of narratives (2010). She finds that postcards displaying images of French colonial presence were combined with "ambiguous and anti-colonial messages" that were in fact commodified, and corresponded with emergence of anti-colonial movements in Morocco (Goldsworthy, 2010, p. 165). Such creative inversions of the colonial medium of postcards, as one postcard project further below will show, lend themselves to a creative approach for teaching purposes. In the following, we introduce examples that take up postcards' multifaceted virtue, and offer inspirations for innovative teaching formats.

\section{Repurposing Postcards for Teaching}

Artists have long used the material (and conceptual) openness of postcards by repurposing them, and thus (re)creating meaning (see McLuhan, 1994). The most prominent example is the Mail Art movement from the 1960s, which included artists that reconfigured postcards, letters and packages as participatory, democratizing interventions into an elitist art world. For artists like Ray Johnson (Johnson, 2020) or Yoko Ono (1971) mail, including postcards, became an open space of creativity. This also allowed for a feminist critique, such as by Eleanor Antin who bypassed the exclusionary space of galleries through her 100 Boots postcard project (The world exists to be put on a postcard, 2019). This body of work was only recently acknowledged in an exhibition at The 
British Museum, attempting to counter a "snobbery about postcards" in the art world (Dawood, 2019, p. n.a.) not unlike Ferguson's argument regarding the social sciences (2005). We here expand on our discussion on the multimodal nature of postcards from one about research to one about pedagogy.

\section{1) Postcards in the classroom}

\section{Data Postcards}

In the context of a data-saturated world, critical approaches to big data, digitization and AI technologies have become an important aspect of teaching in anthropology, sociology, science and technology studies, and related fields. Scholars that engage with the quantification of life and lived realities-be it harnessing statistics of a specific population, or quantified information through face-recognition technologies-often do so from a theoretical point of view: what data is collected, who has access, what happens with all that data?, etc. Data is always made, it is performative, and it moves, constantly (see Thompson, 2004).

Postcards lend themselves well to an applied, methodical exploration of these questions: they are 'open access,' have a wide range of interpretation (and potential for repurposing), and are a traveling item. The Dear Data project offers some practical inspiration. For a year, two information designers, one in London and one in New York, wrote each other a postcard a week for the purpose of getting to know each other (Lupi \& Posavec, n.d.). The correspondents did so by sending analog data from their respective daily lives, which they hand-drew on the front side of postcards, and a key to decipher the visuals on the back side. As the designers explain, they were interested to form "slow data" transmission of daily and personal matters, such as frequency of checking the time, laughter, amount of swearing, etc., to provide a "personal documentary," which also serves as a critique of modes of self-quantification (ibid.). For them, the (visual) data production was not the clearly defined end goal, but rather the starting point to reflect on their lived-in worlds. Since the publication of their book Dear Data (Lupi \& Posavec, 2016) they have invited others, particularly students, to use this method, which has resulted in a vivid global community of postcardists creating and sending their own data (Lupi \& Posavec, n.d.).

Such an exercise can be utilized in applied teaching on topics of ownership and creation of data, quantification and self-reflection, or cross-cultural exchanges, to name a few examples. Moreover, teachers for lower level courses could set specific categories and instruct students to collect data accordingly, e.g. how often they talk to a family member; how often they cook and what; how often they take public transportation/bike/drive a car, etc. The exercise could prompt critical conversations about the nature of data as a context-based, non-neutral measurement. Students self-producing and measuring data may prompt them to think through the complex systems in which data are acquired, constructed, and used in order to perform 'objectivity' and create 'scientific knowledge.' Coupled with lessons on the history of science and data analysis, students could engage in decolonial thought processes that engage issues such as data and race (Zuberi \& Bonilla-Silva, 2008), data and gender (Merry, 2016), data and imperialism (Mann \& Daly, 2019), and data neoliberalism (Day, 2014). The added layer of sending a postcard to someone else can also contribute to lessons about comparative analysis, and prompt processes of understanding everyday life in different parts of the world. While such postcard correspondences may take longer than a semester, such time constraints can be overcome, such as by scanning and emailing postcards parallel to the mailing system, or by sending postcards within a municipality.

\section{Postcards as a Tool of Reflection}

Another example of integrating postcards into teaching is in the context of course reflection. In his large introductory course Computing Cultures at Cornell University, assistant professor in science and technology studies Malte Ziewitz uses postcards in the following way: in the last session of the course, he distributes postcards and asks each student to write a "postcard to your future self."'iiiii Students write down their own addresses and a brief reflection of what they take away from the course. Ziewitz then collects, stamps, and mails the postcards to the students four months later. The underlying thought of this project is to remind students of their learning from a semester before, and to connect it to their current (learning) situation: Does the message capture the students' sense of what was important? Has that changed? Is it still relevant? If not, how come?

Ziewitz's experience has been that the exercise not only helps students recall an important lesson, it also provides an opportunity for them to further engage with topics from the class. While some students share their postcard on social media, others report that they get into conversations with their families or housemates who may see the postcard first when it arrives in the mail. He also realized that for many of his undergraduate students this was the first time that they wrote a postcard-indicating the quite rapid transformation of communication technologies between just two generations. Providing a creative, tangible, and engaging form of course reflection, 
the exercise could include further teaching on the changing practice, materiality, and temporal dimension of communication technologies. In sum, this curious, increasingly less prominent tool of communication can spark conversations among students' social circles—about the course, the things they learned, and perhaps the postcard and communication technologies more generally.

\section{2) Postcards for ethnography: teaching reflexive and relational research}

Another way of teaching with postcards is particularly relevant for students doing ethnographic research—be it close to home, or in faraway places. Postcards can become teachable items that facilitate conversations, guidance, empathic understanding, support and commiseration between advisor and graduate student, or between colleagues who engage in ethnographic field work.

\section{Postcards and Fieldwork}

The parallel between ethnography and postcards is evident in that just as ethnography carries one world into another (Pandian \& McLean, 2017), so do postcards. Indeed, the postcard can be a cross-cutting message that troubles the division between 'field' and 'home' by their very nature as traveling objects. While the practice of 'going' to the field invokes a geographical distance and othering based on the notion that scholars are strangers, isolated, and cut off from the world around them (Simpson, 2009), as a decolonial tool postcards can also trouble this methodological logic that center the western-gaze as legitimate lens for analysis. By prompting students who are beginning their research to search for postcards in their field-sites, teachers can engage them in critical reflection of the stereotyped images and expected encounters. The ensuing dissonance between visual imaginaries and their experiences_-similar to the dissonance between written accounts and ethnographic insights of places, people and certain issues_can provide thought-provoking insight for students.

Another example of how a postcard can interrupt pedagogical norms on ethnography is by fostering dialogue between students and mentors. Rather than accepting the common wisdom in teaching ethnography to send students out on their own in order to 'sink-or-swim' (see Pachirat, 2017), teachers and students can engage in thought-provoking and supportive relationships through the act of sending postcards. The benefits of this type of communication are exemplified in the book Improvising Theory by Allaine Cerwonka and Liisa Malkki, which consists of lengthy email exchanges between a student in her field site and an advisor at the university (2007). Cerwonka, at the time a political science student doing ethnographic fieldwork, remained in contact with her advisor, a cultural anthropologist, in order to better understand the methodology of ethnographic research that was outside of her disciplinary training. Through the immediacy of email exchanges emerged a vivid translation of theory into empirical settings, and vice versa. Postcards may not have this lengthy capacity, but the ethos is similarly one of a mobile exchange between field and classroom, student and teacher, expertise and experiencenot least in order to problematize these binaries. Such exchanges can provide both new theoretical footholds and pedagogical openings for intentional mentorship and scholarly development.

\section{Writing (Postcard) Fieldnotes}

Postcards can also more specifically lend themselves to a teaching tool for writing fieldnotes. French writer and artist Georges Perec provides an enlightening example in his project " 243 cartes postales en couleurs véritables" (1989). Here, he plays with the textual infrastructure of postcards by following a methodical formula of writing fictional postcards that are constrained to five concepts: location; activity; entertainment and satisfaction; specific mention (e.g. thoughts, adventures); and final greeting (Bonch-Osmolovskaya, 2018, p. 254). In this manner, he writes 243 fictive postcards to Italo Calvino by collecting cardboard souvenirs and writing imaginary messages about places he often never visited (in a way reminiscent of Calvino's own Invisible Cities, 1978). Perec accentuates the patterns through his formulaic practice and provides a meta-analysis of what makes a postcard a postcard.

The systematic grouping of what is deemed important information mimics what classifies good ethnographic fieldnotes - a detailed description of location, the actions that take place, reflexivity on the part of the ethnographer, and specificity (Emerson, Fretz \& Shaw, 2011). The postcard can thus be used in class as an exercise for writing fieldnotes as its concise format can prompt students to think of what is important information to be included, how to engage with material objects, and what images may trigger memories for later writing.

Another example of writing postcard fieldnotes comes from the work of one of the authors (Gugganig) as part of a Call for Postcardsiv in which she encouraged her students and colleagues to send postcards from their respective field sites. One colleague wrote an ethnographic vignette on two (identical) postcards from Las Vegas. 
On it, she depicted the momentary experience of sitting in a casino where a conference was hosted, reflecting on how to go about networking in this overly male space. As the sender later shared with Gugganig, writing those postcards was a helpful form of communication that conveyed a sense of closeness in an alienating space. The postcard provides both a space to engage in reflexive scholarship, and may prompt analytical clarity. To some extent, writing a postcard may serve as a 'cover-up' act of writing field notes in the public. The fact that this 'field note' had a recipient—rather than being jotted down for one's own analysis—also changed the way of writing.

\section{The Private-Public Postcard}

Among the submissions to the Call was also an anonymous postcard from the 'field' whose author shared the struggles over the passing of a close research participant and friend (see Fig. 1 and 2). It is an instance that shows how in ethnographic fieldwork the personal and professional cannot so easily be separated. It also suggests that 'formal research' and the more conventional medium of the field notebook or diary may not always be the most fitting medium to 'write away' certain issues. The postcard as a tool of reflection creates an openness that may otherwise not exist.
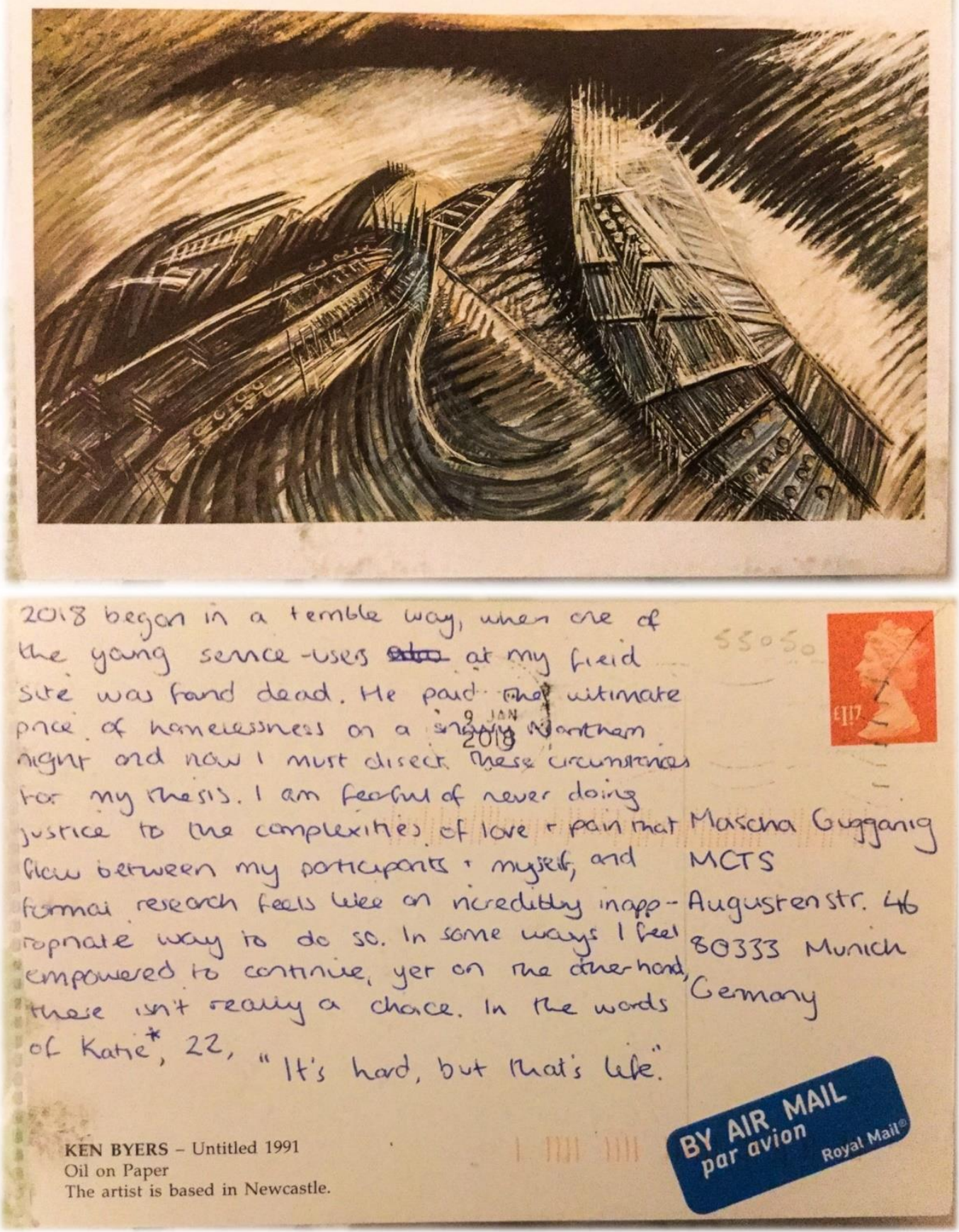

Fig. 1 and 2: Anonymous postcard sent in response to the Call for Postcards. 
This use of postcards is reminiscent of the PostSecret project where people anonymously reveal a secret they otherwise do not feel comfortable sharing (Warren, n.d.). Every week for the last ten years, Frank Warren has received about a hundred postcards from strangers, primarily across the U.S., that has now amounted to approximately 1 million secrets, or as he calls it, an "archive of our hidden selves" (quoted in CBS News, 2014). The act of sharing a secret is also reflected in the senders' diverse methods of 'writing' their postcard. PostSecret cards include collages, text written over images (similar to early postcardists, see Rogan, 2005), or unconventional 'cards' such as ripped up take-away-coffee cups. The semi-public virtue of postcards (Östman, 2006) is evident in that the implicit publicness becomes explicit—a public performance of private secrets. These anonymous, yet open proclamations of shame may create relations and bonds among strangers with similar secrets.

Both the above anonymous postcard and the PostSecret postcards repurpose postcards as medium of relationality and emotional exchange. Postcards can thus take on the role of reflexive ethnographic fieldnotes for a researcher to process her experience of fieldwork, for instance in a conflict zone (Wood, 2006). Schor's project "Greetings from the [un] Holy Land" does this by using postcards as a vessel for reflection and a prompt for critiquing the normalization of quotidian violence in Israel and Palestine and highlights the tension between daily life and idealized images of it (Schor, 2017). Beyond the purposes of communication, repurposing postcards in this way can reveal the chasm between representation and one's own lived experiences. The dissonance between time and place creates new connections between the real and the theoretical. And the tangible materiality of the postcard confirms that what was experienced actually happened.

\section{3) Postcards for community-based work and teaching}

Postcards can also offer fruitful engagements in collaborative, community-based research and teaching. Indeed, in an ever-increasingly globalized world, the postcard is a multifaceted medium that offers playful exchange and connections between people. Interactive research formats combined with community work are growing in prominence, and an example for this is Lydia Degarrod's arts-based ethnographic exhibition Geographies of the Imagination (2013). Here, participants were engaged to share their migratory routes on a world map, thus helping to form the exhibition. Community-based research and engagement like this emphasize process rather than outcome (Tuhiwai-Smith, 2012, p. 130), and postcards can serve as a teaching tool on these processes, as the following projects show.

\section{Hawai $i$ beyond the Postcard}

As part of her research on 'aina (colloquially 'land' in Hawaiian) relations and agricultural biotechnology on Kaua'i, Gugganig developed a traveling exhibition that had postcards at its core (Gugganig, 2016). The postcards depicted self-made images and interview quotes from a variety of interlocutors, while turning around the printing process: the image was on the matte side, the text on the glossy side. This conceptual inversion reflected her effort to decolonize the exoticizing 'othering' of the common picture postcard image of Hawai'i (Mamyia, 1992), and to instead display the lived realities and voices she encountered throughout fieldwork. This inversion of stereotyping depictions also had a different element that emerged throughout the eight locations in which the exhibition was shown: in each place, Gugganig asked visitors to write their reflections on the topics of food, land use and biotechnology on conventional postcards (among others, of Chicago, Vancouver, Vienna, etc.) that she would then send to the next exhibition location, where they eventually became part of the exhibition. The exhibition grew to include about 50 additional postcards, which both 'rewrote' the function of a postcard, and, through this participatory element highlighted the processual dimension of knowledge production.

\section{Postcards from the Diaspora}

Another participatory postcard approach is part of the film "Wenn wir erst tanzen" (Once we Dance) (Lienig, Heth, \& Winkler, 2018). The film portrays a dance group in Hoyerswerda that regains self-worth after the declining coal industry had turned the town into the fastest-shrinking town in Germany. The filmmaker team invited the diaspora of Hoyerswerda around the world to send postcards and share a story of the place they had moved to, or a memory of their time in Hoyerswerda. In one scene, the viewer sees over 200 postcards from former residents, installed on various poles on a site of a formerly demolished house (see Fig. 3 and 4). Most postcard stories are of Hoyerswerda (and not of the place they moved to), which filmmaker Dirk Lienig noted as 
significant. In the dominance of Hoyerswerda stories, its residents— who shared a sense of being 'left behind'saw that people did not necessarily want to leave, but that they often had to. ${ }^{\mathrm{v}}$
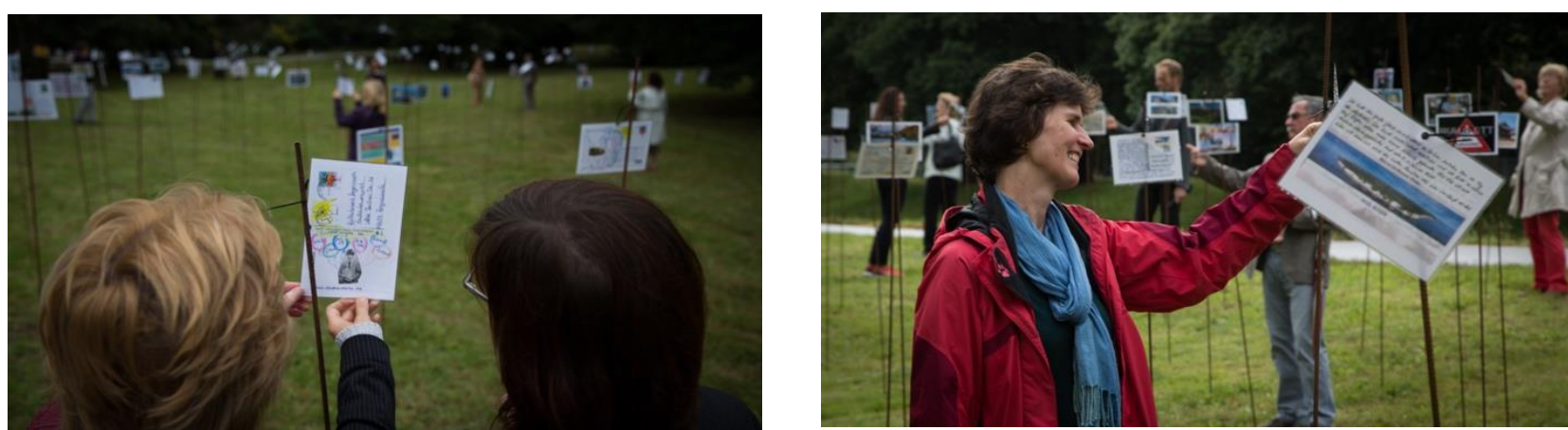

Fig. 3 and 4: Stills from the film "Wenn wir erst tanzen" in which residents of Hoyerswerda (Germany) read postcards from the worldwide diaspora (kindly provided by Dirk Lienig).

What is remarkable about this use of postcards is the material, tactile dimension of this 'dataset,' which would have looked very different were it gathered through a more conventional method, like a survey. The postcards here are multimodal in an engaging and collaborative (anthropological) sense (Collins, Durington, \& Gill, 2017), where memories preserved on postcards can bring about unspoken sentiments and stories of living in a placeHoyerswerda. Furthermore, the pictorial dimension of postcards—images from Sydney, Korea, Berlin—offered an evocative, visual sense of the community, now dispersed across the globe as a diaspora.

These various examples show that postcards have a discursive, material, practical and normative openness, which offers creative, nonlinear inspirations for teaching; on ethnography, fieldwork, fieldnote writing, and community and collaborative work.

\section{Conclusion}

We draw a metaphor from postcards to ethnographic work and pedagogical innovations by arguing that just as the role of the postcard extends beyond the framed image, so too does research, teaching, and our engagement as scholars in the world. Postcards offer pedagogical potential for aesthetic-based, decolonizing reflections and learning by informing our students to ask: What is erased? What structures of power have influenced the image that is displayed? What systems influence the interpretation of images and text? How does a postcard travel? How are the messages understood contextually, historically, socio-culturally, and personally? We further argue that postcards can be used as a tool of relationship building between mentors and students in the field, and more broadly in the discipline in order to create a community that can overcome the oft-isolated nature of ethnographic work-perhaps also within an ethnographic field site. Finally, we propose that postcards can also be used in collaborative research and community-based teaching.

This article also raises the question of what counts as scholarship, and where other, emotional labor ought to find a home. In the context of ethnographic fieldwork and an academic system that dictates what is an acceptable format of reflection, postcards may provide an opening for issues, concerns, feelings, or preliminary thoughts. We understand education as an ongoing project, and see teaching and learning as an iterative, coconstitutive process. Thanks to its conceptual and material openness, the postcard can be used in multifarious ways to achieve these aims.

\section{Acknowledgements}

Mascha Gugganig would like to thank the \#Colleex collective, a collaboratory for ethnographic experimentation, for supporting the Call for Postcards, and everyone who kindly send their postcard(s). She would also like to thank Dirk Lienig for providing images of their film "Wenn wir erst tanzen" (Fig. 3 and 4), Malte Ziewitz from Cornell University who offered additional information and thoughts for his teaching, as well as her colleague who wrote and co-reflected on her ethnographic postcards from Las Vegas. 


\section{References}

Adjin-Tettey, E., Calder, G., Cameron, A., Deckha, M., Johnson, R., Lessard, H., Maloney, M., \& Young, M. (2008). Postcard from the edge (of empire). Social \& Legal Studies, 17(1), 5-38.

Albers, P. C., \& James, W. R. (1988). Travel photography: A methodological approach. Annals of Tourism Research, 15(1), 134-158.

Allen, J, \& Rumbold, J. (2004). Postcard conversations: A dialogue about methodology. Qualitative Research Journal, 4(2), 100-142.

Alloula, M. (1986). The colonial harem. University of Minnesota Press.

Andriotis, K., \& Mavrič, M. (2013). Postcard mobility: Going beyond image and text. Annals of Tourism Research, 40, 18-39.

Baldwin, B. (1988). On the verso: Postcard images as a key to popular prejudices." Journal of Popular Culture, 22(3), 15-28.

Berger, J. \& Mohr, J. (1982). Another way of telling. Pantheon Press.

Bonch-Osmolovskaya, T. (2018). Combinatorial greetings from Georges Perec. [Paper presented] Bridges 2018

Conference Proceedings, Stockholm, Sweden. https://archive.bridgesmathart.org/2018/bridges2018-253.pdf.

Brady, T. J. (1969). Postcards and history. History Today, 19(12), 848-855.

Burns, P. M. (2004). Six postcards from Arabia: A visual discourse of colonial travels in the Orient." Tourist Studies, 4(3), 255-75.

Cerwonka, A., \& Malkki, L. H. (2007). Improvising theory: process and temporality in ethnographic fieldwork. University of Chicago Press.

Calvino, I. (1978). Invisible cities. Houghton Mifflin Harcourt.

CBS News. (2014). Tell me a secret: How PostSecret shares anonymous messages with the world. CBS Sunday Morning, https://www.youtube.com/watch?v=lbM3tUY0CUI\&feature=youtu.be.

Collins, S. G., Durington, M., \& Gill, H. (2017). Multimodality: An invitation: Multimodal anthropologies. American Anthropologist, 119(1), 142-146.

Dawood, S. (2019, February 13). There is a snobbery about postcards': British Museum explores overlooked art form. Design Week. https://www.designweek.co.uk/issues/11-17-february-2019/there-is-a-snobbery-aboutpostcards-british-museum-explores-overlooked-art-form/

Day, R. E. (2014). Indexing it all: The subject in the age of documentation, information, and data. MIT Press

Degarrod, L. N. (2013). Making the unfamiliar personal: Arts-based ethnographies as publicengaged ethnographies. Qualitative Research, 13(4), 402-413.

Emerson, R. M., Fretz, R. I., \& Shaw, L. L. (2011). Writing ethnographic fieldnotes. University of Chicago Press.

Ferguson, S. (2005). 'A murmur of small voices': On the picture postcard." Academic Research Archivaria, Fall JI (60), 167-84.

Gugganig, M. (2016). Hawai i beyond the postcard. https:// hawaiibeyond.wordpress.com/

Gillen, J. (2013). Writing Edwardian postcards. Journal of Sociolinguistics, 17(4), 488-521. 
Goldsworthy, P. (2010). Images, ideologies, and commodities: the French colonial postcard industry in Morocco. Early Popular Visual Culture, 8(2), 147-167.

Hall, N., \& Gillen, J. (2007). Purchasing pre-packed words: complaint and reproach in early British postcards. In M. Lyons (Ed.) Ordinary Writings, personal narratives: Writing practices in the 19th and early 20th-century Europe, (pp.101117). Peter Lang.

Iken, K. (2019, January 1). WhatsApp der Kaiserzeit. Spiegel Online. https://www.spiegel.de/geschichte/postkartewird-150-die-whattsapp-der-kaiserzeit-a-1288738-amp.html

Johnson, R. (2020). Mail Art \& Ephemera. Ray Johnson Estate. http://www.rayjohnsonestate.com/art/mail-artand-ephemera/

Kelly, V. (2004). Beauty and the market: Actress postcards and their senders in early twentieth-century Australia. New Theatre Quarterly, 20(2), 99-116.

Lienig, D, Heth, D., \& Winkler, O. (Directors). (2018). Wenn wir erst tanzen [Once we are Dancing] [Film]. Contract 99.

Lupi, G., \& Posavec, S. (n.d). Dear Data, http://www.dear-data.com/theproject.

Lupi, G., \& Posavec, S. (2016). Dear data. Princeton Architectural Press.

Mamiya, C. J. (1992). Greetings from Paradise: The Representation of Hawaiian Culture in Postcards. Journal of Communication Inquiry, 16(2), 86-101.

Mann, M., \& Daly, A. (2019). (Big) data and the North-in-South: Australia's informational imperialism and digital colonialism. Television \& New Media, 20(4), 379-395.

McLuhan, M. (1994). Understanding Media: The Extensions of Man. MIT Press.

Merry, S. E. (2016). The seductions of quantification: Measuring human rights, gender violence, and sex trafficking. University of Chicago Press.

Moors, A., \& Machlin, S. (1987). Postcards of Palestine: interpreting images. Critique of Anthropology, 7(2), 61-77.

Moran, J. (2005, August 29). Hello, I'm Here and You're There. New Statesman.

https://www.newstatesman.com/node/162713

Ono, Y. (1971). A Hole to See Through, Yoko Ono '71 Postcard. Artists Books and Multiples.

http://artistsbooksandmultiples.blogspot.com/2014/09/yoko-ono-hole-to-see-sky-through.html

Östman, J. (2006). The postcard as media. Text \& Talk - Interdisciplinary Journal for the Study of Discourse, 24(3), 423442.

Pachirat, T. (2017). Among wolves: Ethnography and the immersive study of power. Routledge.

Pandian, A., \& McLean, S. J., (Eds). (2017). Crumpled Paper Boat: Experiments in ethnographic writing. Duke University Press.

Peterson, N. (1985). The popular image. In I. Donaldson \& T. Donaldson (Eds.), Seeing the First Australians, (pp.164-180). George Allen and Unwin.

Perec, G. (1989). Deux cent quarante-trois cartes postales en couleur véritables, in L'infra ordinaire, (pp. 33-68). La librairie du XX ${ }^{\circ}$ siècle, Le Seuil. http://243postcards.canalblog.com 
Ripert, A., \& Frère, C. (1983). La carte postale : son histoire, sa fonction sociale. Presses Universitaires du Lyon. Éditions du CNRS.

Rogan, B. (2005). An entangled object: the picture postcard as souvenir and collectible, exchange and ritual communication. Cultural Analysis, 4(Annual 2005), 1-27.

Schor, S. (2017). Greetings from the [un] Holy Land. Sophie Schor. www.sophieschor.com/unholyland

Simpson, B. (2009). Messages from the Field. Anthropology Today, 25(5), 1-3.

Staff, F. (1966). The picture postcard and its origins. Lutterworth Press.

The British Museum (2019) The world exists to be put on a postcard [Exhibition]. https://blog.britishmuseum.org/the-world-exists-to-be-put-on-a-postcard/

Thompson, C. (2004). Co-producing CITES and the African elephant. In S. Jasanoff (Ed.), States of knowledge: The co-production of science and social order, (pp. 67-86). Routledge.

Tuhiwai-Smith, L. (2012). Decolonizing methodologies: Research and indigenous peoples (2nd ed.). Zed Books.

Urry, J. (1990). The tourist gaze: Leisure and travel in contemporary societies. Sage.

Waitt, G., \& Head, L. (2002). Postcards and frontier mythologies: Sustaining views of the Kimberley as timeless. Environment and Planning D: Society and Space, 20(3), 319-344.

Warren, F. (n.d). PostSecret. https://postsecret.com/

Wood, E. J. (2006). The ethical challenges of field research in conflict zones. Qualitative Sociology, 29, 373386.

Zuberi, T. \& Bonilla-Silva, E. (Eds.). (2008). White logic, white methods: Racism and methodology. Rowman \& Littlefield Press.

\section{Notes:}

${ }^{i}$ Gugganig \& Schor, manuscript under review, American Anthropologist.

ii Information and reflections on this course are based on personal conversations between Gugganig and Malte Ziewitz.

iii See https://colleex.wordpress.com/colleex-open-formats/postcards-and-ethnography/

iv Filmmaker Lienig responded to a question by Gugganig in the Q\&A session of the premiere film screening at the Munich Dok Film Festival, May 2019. He kindly provided screenshots (Fig. 3 and 4) for this article.

v Filmmaker Lienig responded to a question by Gugganig in the Q\&A session of the premiere film screening at the Munich Dok Film Festival, May 2019. He kindly provided screenshots (Fig. 3 and 4) for this article. 